Biological and Applied Sciences

Vol.60: e17160341, January-December 2017 http://dx.doi.org/10.1590/1678-4324-2017160341 ISSN 1678-4324 Online Edition

\title{
Microscopic Studies on Erythrocytes of Channa punctata Exposed to Commercial Grade Lindane
}

\author{
Debasish Bhattacharjee ${ }^{1}$, Suchismita Das ${ }^{1 *}$. \\ ${ }^{1}$ Assam University - LifeScience and Bioinformatics Silchar, Assam, India.
}

\begin{abstract}
Light and scanning electron microscopic studies of erythrocytes of Channa punctata exposed to two sublethal doses of lindane over a period of 21 days revealed myriads of anomalies. High frequency of micronucleus appeared progressively in the erythrocyte, ranging from 3.8-7.5\%, when monitored weekly for $21 \mathrm{~d}$ at $0.25 \mathrm{~g} / \mathrm{L}$ and $1.0-3.0 \%$ at $0.025 \mathrm{~g} / \mathrm{L}$ lindane. Prominent structural anomalies of erythrocytes included abnormal shapes, vacuolation, membrane invagination and disintegration. At higher dose and at later duration, a unique tendency of abnormal cells to stick together was observed. It could be concluded that commercial formulation of lindane could induce genotoxicity and structural anomalies in the erythrocytes of fish.
\end{abstract}

Key words: RBC, SEM, light microscopy, micronucleus

\footnotetext{
*Author for correspondence: drsuchismita9@gmail.com,das_aus@rediffmail.com
} 


\section{INTRODUCTION}

Lindane ( $\gamma$-hexachlorocyclohexane) is a broad spectrum, environmentally persistent organochlorine pesticide that has been banned or restricted for use in several countries, including India $\left.{ }^{1,2}\right]$. However, lindane and its residues have been regularly detected in drinking water, industrial effluent and sewage, predominantly due to its continued usage via domestic stockpile or due to its tendency to bioaccumulate in natural waters $\left[{ }^{3,4}\right]$. Often such residues in water effects non-target organisms such as fish, consequently effecting human health. Fish can take up lindane or its residue from water and sediments and bioaccumulation in their fatty tissues $\left[{ }^{5}\right]$, which could be associated to its hydrophobicity and persistency in the environment $\left[{ }^{6}\right]$. Blood is an excellent indicator of lindane stress in fish $\left.{ }^{7}\right]$ and the use of erythrocyte alterations in fish are considered a useful tool to evaluate pathological processes resulting from exposure to environmental pollutant $\left[{ }^{8}\right]$. Both light (LM) and scanning electron microscopic (SEM) studies have been used to detect cellular alteration in erythrocytes in response to aquatic pollution $\left.{ }^{9}\right]$. LM aids in the identification of micronuclei (MN), nuclear abnormalities, and histopathological alterations, while, SEM is used for the assessment of alterations in cells at surface microstructural and internal fine structural level. Generally, MN is formed by the condensation of whole or fragmented chromosomes that are not incorporated into the main nucleus during mitosis, due to aneugenic or clastogenic effects $\left[{ }^{10}\right]$. MN test has been found to be a sensitive assay to evaluate the effects of genotoxic compounds in fish under controlled conditions $\left[{ }^{11}\right]$. Thus, the present study aims to analyse the temporal dynamics of erythrocyte morphology in a freshwater teleost, Channa punctata exposed to sublethal commercial formulations of linadane (effective concentration of 6.5\%) using both light and scanning electron microscope.

\section{MATERIAL AND METHODS}

\section{EXPERIMENTAL SET-UP}

Healthy Channa punctata (length, $16.58 \pm 0.3 \mathrm{~cm}$, and weight, $25.7 \pm 0.5 \mathrm{~g}$ ) were procured from a local fishery with no reported pollution load. They were acclimatized for 3 weeks in $1000 \mathrm{~L}$ cement tank, under laboratory conditions with tap water free from chlorine, with the physicochemical characteristics such as temperature, $\mathrm{pH}$, dissolved oxygen, and hardness $\left.\left(\mathrm{as}^{\mathrm{CaCO}}\right)_{3}\right)$ to be $29.2 \pm 0.13^{\circ} \mathrm{C}$, $6.8 \pm 0.3,5.5 \pm 0.24 \mathrm{mg} \mathrm{L}-1$ and $30.5 \pm 0.5 \mathrm{mg} \mathrm{L}-1$, respectively and fed with minced goat liver at the rate of $3 \%$ body weight. Stock solution of commercially available lindane was prepared from Gamma BHC 6.5\% (trade name -Kunahex) procured from Kundu Agro Chemicals Ltd., Kolkata, India and purchased from a local shop (Tuhina Seeds).

In an initial study, $96 \mathrm{~h}$ LC50 was found to be $2.55 \mathrm{~g} \mathrm{~L}-1$. Stock solutions of the test substance were prepared by dissolving the insecticide in the tap water. These solutions were further diluted to obtain the experimental concentrations in aquariums. Adult fish were exposed to two different sub-lethal concentrations of lindane $(0.025 \mathrm{~g} \mathrm{~L}-1$ and $0.25 \mathrm{~g} \mathrm{~L}-1)$ for 7,14 and 21 days after acclimatization period. The concentration of lindane in the water samples was determined thrice during the course of 21 days of experimentation by gas liquid chromatography (Nucon 5765) equipped with 63Ni electron capture detector (ECD) as per Singh and Singh $\left.{ }^{4}\right]$.

The mean concentration was always within $5 \%$ of the intended concentration. A total of 45 fishes, divided into three groups (one control and two experimental groups), 
were kept in three separate containers, each of 200 L capacity. Lindane free tap water served as control media. Control and experimental fish were fed daily

as described earlier. No mortality was observed during the experiments. Experimental and control water was refreshed every day to minimize loss of pesticide concentration. From treatment and control tanks, 5 fish were sacrificed every 7,14 and 21 days.

\section{LIGHT MICROSCOPY}

Blood was drawn with a heparinized syringe from the caudal peduncle. The smears on grease free slides were fixed in absolute methanol for $10 \mathrm{~min}$ after drying at room temperature. Slides were stained with haematoxylin and eosin, followed by dehydration in ascending grades of alcohol [12]. Several slides were selected on the basis of staining quality, then coded, randomized and scored blindly. In each group 10,000 cells (a minimum of 2000 per slide, $n=5$ ) were examined [10] at 40x objective and 10x eyepiece for morphologically altered erythrocytes and micronucleus. Semi quantitative scoring of morphological anomalies were performed and the mean prevalence of each parameters was categorized as none (-), mild $(+)$, moderate $(++)$ or severe $(+++)$ as per Velmurugan et al. [13]. The established criteria for identifying micronucleus [14] were strictly followed to ensure authentic scoring.

\section{SCANNING ELECTRON MICROSCOPY}

Two to three drops of blood were put inside a vial containing $2.5 \%$ glutaraldehyde prepared in $0.1 \mathrm{M}$ sodium cacodylate buffer. The sample was centrifuged at 1,500 rpm for 5 min, washed, and re-suspended in distilled water, and the process was repeated two to three times. A thin film was decanted and applied to a cover slip after resuspension in distilled water [15]. The samples were then air dried and coated with gold in a JFC-1100 (JEOL Ltd., Tokyo, Japan) ion sputterer. Observations were made on a JSM-6360 (JEOL) SEM at an accelerating voltage of $15-20 \mathrm{kV}$, using the secondary electron emission mode. Blood smear samples from 5 control and 5 lindane-exposed fish were studied, and the average percentage of abnormal cells were calculated.

\section{ETHICAL CLEARANCE}

Ethical guidelines from the Canadian Council on Animal Care [16] were followed that include the following: a minimum number of fish were used for experimentation, fish were maintained in properly aerated aquaria in a quiet and well-ventilated room, crowding was avoided; an adequate amount of nutritious food was provided; fish were handled gently and only when necessary; aquaria were covered with nets as $C$. punctata has the habit of jumping out and suffer mortality. The above mentioned process has the necessary recommendations of Assam University Institutional Ethical Committee.

\section{STATISTICAL ANALYSIS}

Basic statistics such as mean and standard error were computed. One-way analysis of variance (ANOVA) was performed to determine whether treatments were significantly different from the control group $(\mathrm{P}<0.05)$.

The Tukey test was considered for multiple comparisons. In all the cases, SPSS 19 statistical software for windows was used.

\section{QC/QA}

Certified reference standard from Sigma (USA) was used for the quantification of lindane. The target analytes were identified in the sample extract by comparing the 
retention time from the standard mixture and quantified using the response factors from five level calibration curves of the standard. Procedural blanks (analyte concentrations were less than method detection limit), random duplicate samples (Standard deviation <5), and matrix spike recovery of $100 \pm 20 \%$ was practiced.

\section{RESULTS AND DISCUSSION}

Erythrocytes in $C$. punctata are nucleated, biconvex and are the dominant cell type in the blood. Table 1 summarized the semi quantitative analysis of erythrocyte deformities from lindane treated $C$. punctata at various exposure durations and concentrations. The common deformities were various abnormal shapes of erythrocytes such as elongated with membrane invagination, which showed variable degree of abnormalities.

At $0.25 \mathrm{~g} / \mathrm{L}$, at the end of 21 days of exposure, the abnormal cells showed a tendency towards sticking to each other. Appearance of MN was another prominent feature observed in the cells during later exposure durations. Some of the cells showed vacuolation.

Table 1 Semi quantitative analysis of erythrocyte abnormalities from lindane treated C. punctata at various exposure

durations and concentrations

\begin{tabular}{|c|c|c|c|c|c|c|c|}
\hline \multirow{3}{*}{$\begin{array}{l}\text { Lesion } \\
\text { Abnormal shapes }\end{array}$} & \multirow{3}{*}{$\begin{array}{l}\text { Control } \\
\\
-\end{array}$} & \multirow{2}{*}{\multicolumn{2}{|c|}{$\begin{array}{l}\text { 7-d } 14-\mathrm{d} 21-\mathrm{d} \\
0.255 \mathrm{~g} / \mathrm{L}\end{array}$}} & & \multirow{2}{*}{\multicolumn{2}{|c|}{$\begin{array}{l}7-\mathrm{d} 14-\mathrm{d} \\
0.025 \mathrm{~g} / \mathrm{L}\end{array}$}} & \multirow{3}{*}{$\begin{array}{l}21-\mathrm{d} \\
\\
++\end{array}$} \\
\hline & & & & & & & \\
\hline & & + & ++ & +++ & + & ++ & \\
\hline Membrane invagination & - & ++ & +++ & +++ & + & ++ & +++ \\
\hline Micronucleus & - & + & ++ & +++ & - & + & ++ \\
\hline Vacuolation & - & - & + & + & - & - & - \\
\hline Cytoplasmic blebs & - & - & + & + & - & - & - \\
\hline Lobopodium & - & - & - & ++ & - & - & - \\
\hline Acanthocyte & - & - & - & + & - & - & - \\
\hline $\begin{array}{l}\text { Membrane } \\
\text { disintegration }\end{array}$ & - & - & + & +++ & - & - & - \\
\hline Sticky cells & - & - & - & ++ & - & - & - \\
\hline
\end{tabular}

- none, + mild, ++ moderate, +++ severe occurence

The scoring of MN was performed and percent values were shown in Table 2. High statistical significance $(\mathrm{p}<0.01)$ were observed between $\mathrm{MN}$ frequencies of control and lindane treated groups. Besides, statistical significance $(p<0.05)$ were observed between exposure durations at a particular dose, indicating progressive appearance of $\mathrm{MN}$ in erythrocytes as the duration of exposure increased. The highest $\mathrm{MN}$ frequency was observed after 21 days of exposure to $0.255 \mathrm{~g} / \mathrm{L}$ lindane, which accounted for around $7.5 \%$. Similarly, for this dose, there was around $4.5 \%$ and $3.8 \% \mathrm{MN}$ frequencies at 14 and 7 days of exposure, respectively. At $0.025 \mathrm{~g} / \mathrm{L}$, there were appearance of around 1.0\%, 2.3\% and 3.2\% MN after 7, 14 and 21 days of exposure. 
Microscopic analysis of fish blood

Table 2 Micronucleus frequency (mean \pm SD) \% in erythrocyte of $C$. punctata at various exposure durations and concentrations of lindane

\begin{tabular}{llll} 
Test & $7-\mathrm{d}$ & $14-\mathrm{d}$ & $21-\mathrm{d}$ \\
\hline Control & $0.15 \pm 0.23$ & $0.1 \pm 0.008$ & $0.12 \pm 0.03$ \\
$0.255 \mathrm{~g} / \mathrm{L}$ & $3.8 \pm 0.12^{*}$ & $4.5 \pm 0.11^{*}$ & $7.5 \pm 0.3^{*}$ \\
$0.025 \mathrm{~g} / \mathrm{L}$ & $1.0 \pm 0.05^{*}$ & $2.3 \pm 0.21^{*}$ & $3.2 \pm 0.03^{*}$ \\
\hline
\end{tabular}

*indicates significance at $\mathrm{p}<0.05$

Figures $1 \mathrm{~A}$ and $3 \mathrm{~A}$ indicated the light and electron micrograph of the blood of fish under controlled condition, respectively. Under, LM, prominent changes observed at $0.25 \mathrm{~g} / \mathrm{L}$ lindane included abnormal shapes (hooked and irregular membrane), vacuolation and appearance of $\mathrm{MN}$ after $7 \mathrm{~d}$. At later exposure durations, some blebs in the cytoplasmic, severe membrane invagination and slight lobopodial projections appeared in the erythrocytes. Some of the abnormal cells developed a tendency towards sticking to each other followed by membrane disintegration (Figs. 1B-D). At $0.025 \mathrm{~g} / \mathrm{L}$ lindane exposure (Figs. 2A-C), similar abnormalities were observed although, with lesser severity. Besides, sticky cells were not found at this dose, at any duration. Under SEM, at $0.25 \mathrm{~g} / \mathrm{L}$, erythrocytes showed various abnormal shapes, membrane invagination, echinocytes, lobopodial projections and disintegrated membranes (Figs. 3 B-F). At $0.025 \mathrm{~g} / \mathrm{L}$ lindane, some typical abnormalities were the appearance of echinocytes and severe membrane invaginations in erythrocyte membranes (Figs. 4 A-D).
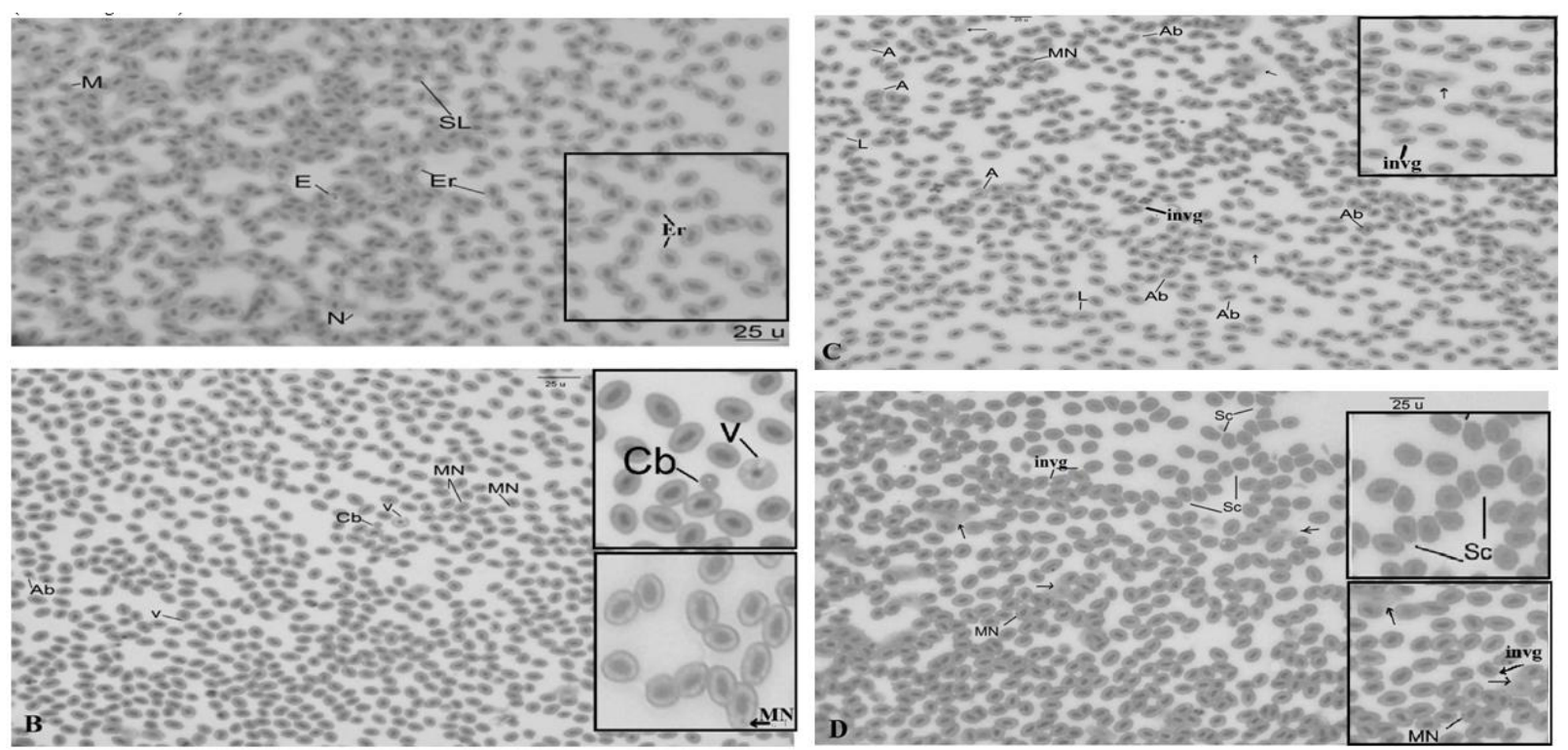

Fig. 1 Light micrograph of blood of $C$. punctata $(\mathrm{H} \& \mathrm{E}, \times 400)$ : (A) control- nucleated erythrocytes (Er), eosinophil (E), neutrophil (N), small lymphocyte (SL) and monocyte (M); (B) abnormal shapes (Ab), vacuolation (v), micronucleus $(\mathrm{MN})$ and cytoplasmic bleb $(\mathrm{Cb})$ after $7 \mathrm{~d} ;(\mathrm{C})$ abnormal shapes $(\mathrm{Ab})$, erythrocyte membrane invagination (invg), acanthocytes (A), lobopodium (L), micronucleus (MN) and membrane disintegration (arrow) after $14 \mathrm{~d}$; (D) sticking (Sc), abnormal shapes (Ab), membrane invagination (invg), micronucleus (MN) and disintegrated membrane (arrow) after $21 \mathrm{~d}$ of exposure to $0.25 \mathrm{~g} / \mathrm{L}$ lindane (inset-enlarged view). 

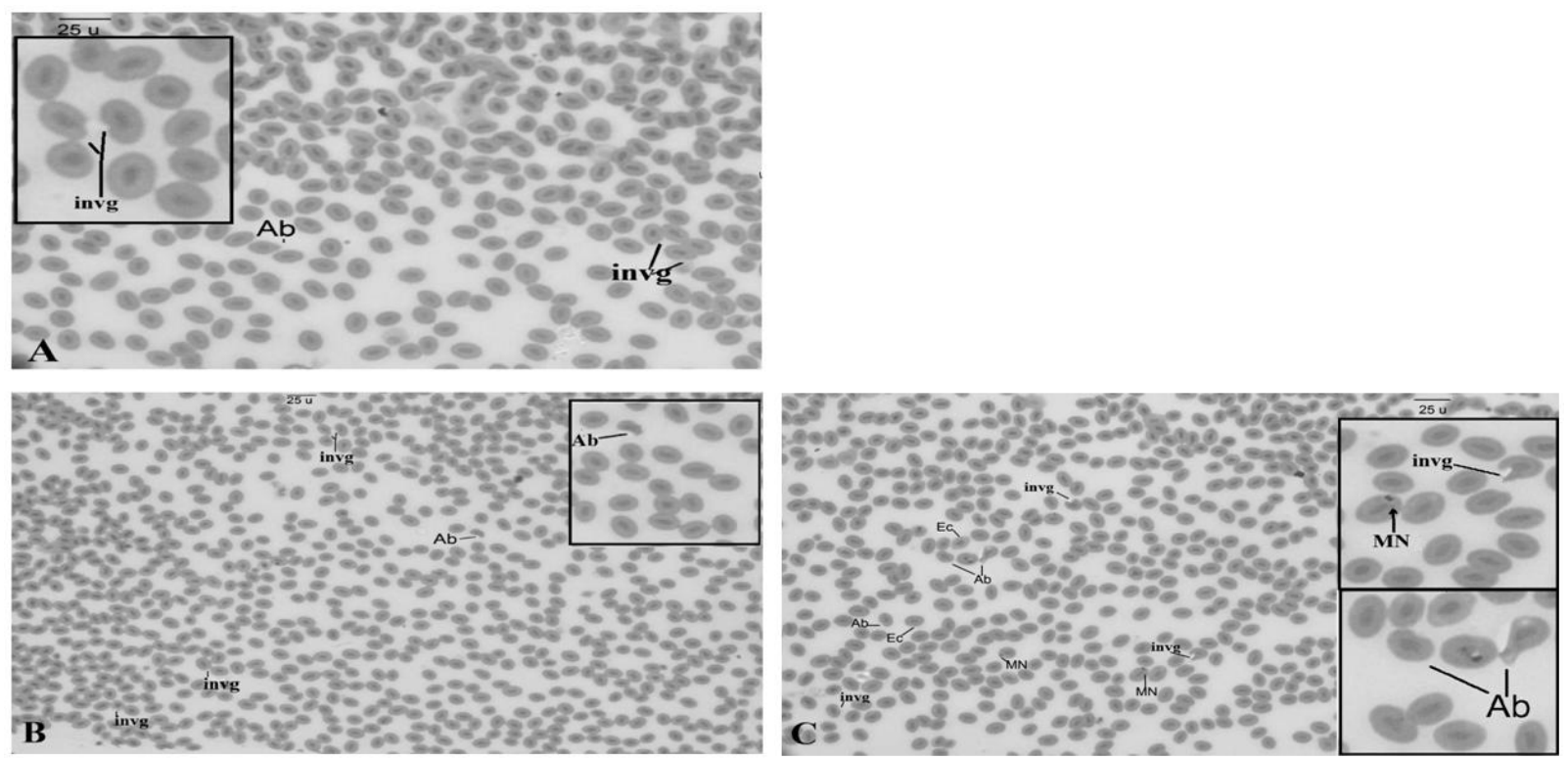

Fig. 2 Light micrograph of blood of $C$. punctata $(\mathrm{H} \& \mathrm{E}, \times 400)$ : showing (A) abnormal shapes (Ab) and erythrocyte membrane invagination (invg) after $7 \mathrm{~d}$; (B) after $14 \mathrm{~d}$; (C) abnormal shapes (Ab), membrane invagination (invg), echinocytes (Ec) and micronucleus (MN) after 21 days of exposure to $0.025 \mathrm{~g} / \mathrm{L}$ lindane (inset-enlarged view).
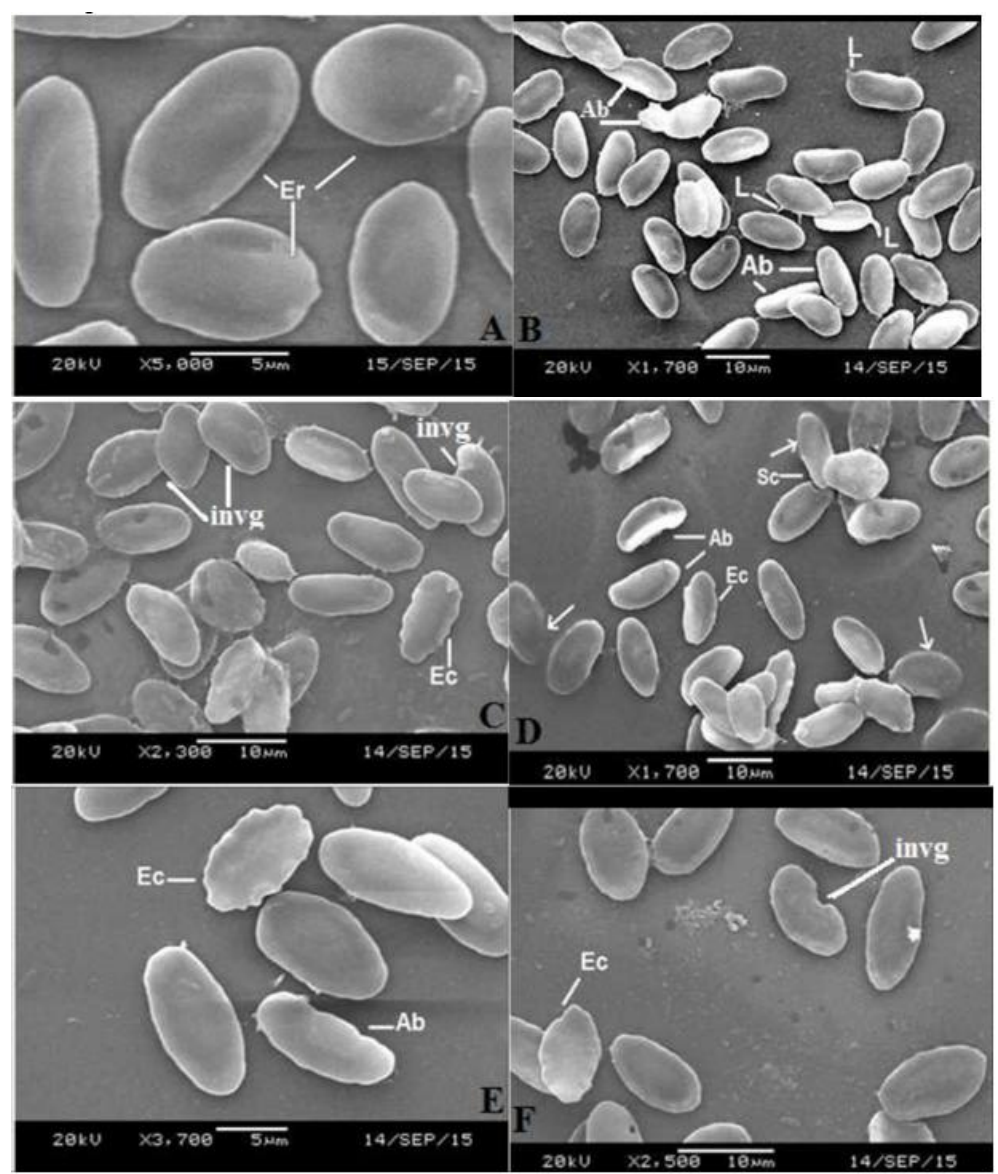

Fig. 3 SEM of blood of $C$. punctata (A) under control condition showing oval erythrocytes $(\times 5000)$; (B) abnormal shapes $(\mathrm{Ab})$ and lobopodial projections after 7 days $(\times 1,700)$; $(\mathrm{C})$ membrane invagination (invg) after $14 \mathrm{~d}(\times$ 2,300); (D) stickiness ( $\mathrm{Sc}$ ), abnormal shapes (Ab), membrane invagination (invg), and disintegrated membrane (arrow) $(\times 1,700)$ after $21 \mathrm{~d}$; (E) Echinocytes $(\mathrm{Ec})$ and slender erythrocyte $(\mathrm{Ab})(\times 3,700)$ after 21 days; (F) membrane invagination (invg) and echinocytes $(\times 2,500)$ after 21 days of exposure to $0.25 \mathrm{~g} / \mathrm{L}$ lindane. 

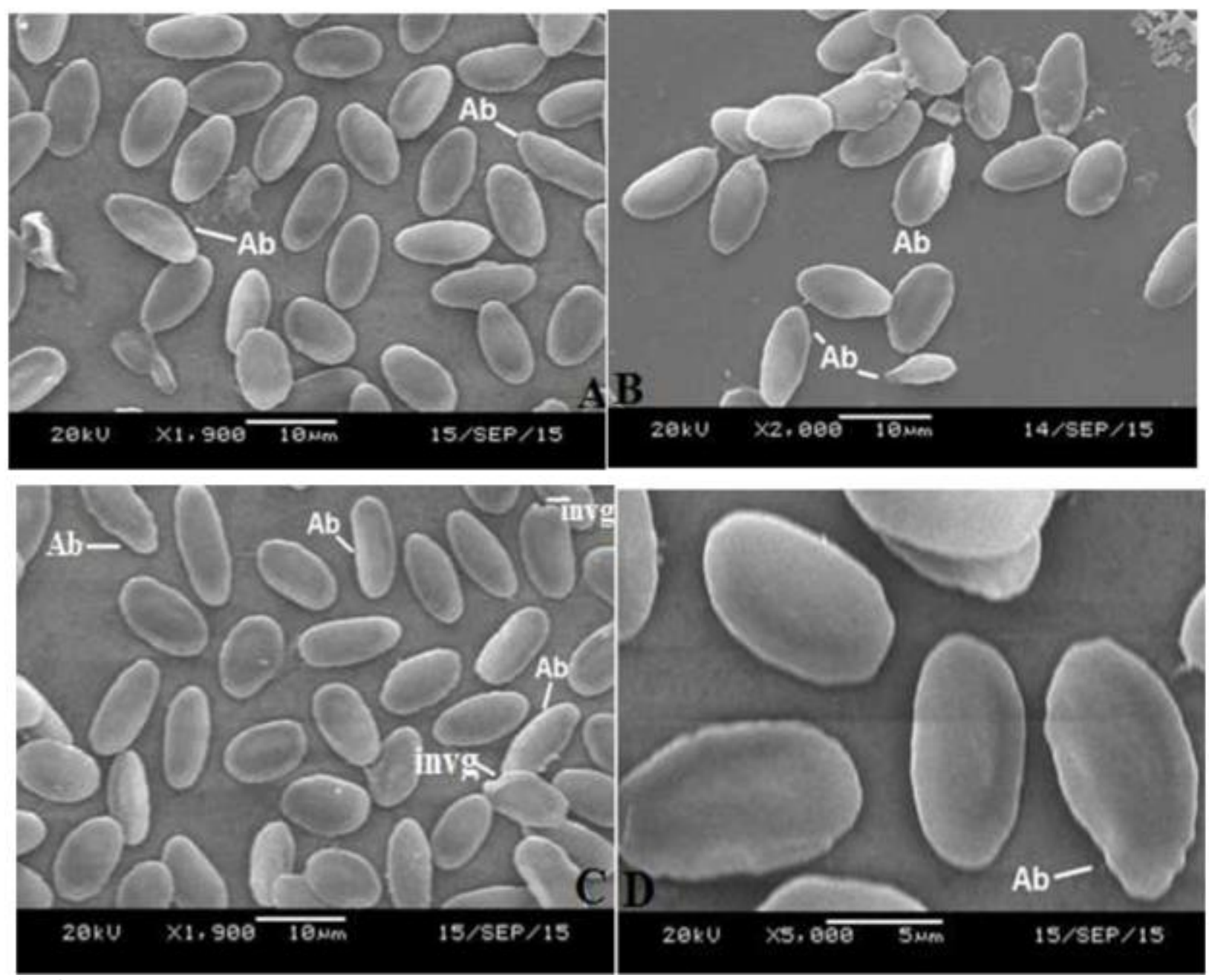

Fig. 4 SEM of erythrocytes of $C$. punctata showing (A) abnormal shapes (Ab) after 7 days (×1, 900); (B) abnormal shapes $(\mathrm{Ab})$, and clumps after 14 days $(\times 2,000)$; $(\mathrm{C})$ abnormal shapes $(\mathrm{Ab})$ and membrane invagination (invg) $(\times 1,900)$ after $21 \mathrm{~d}$; (D) enlarged abnormal shape $(\times 5,000)$ after 21 days of exposure to $0.025 \mathrm{~g} / \mathrm{L}$ lindane.

Erythrocytes are chiefly responsible for gaseous exchange and excretion of nitrogenous wastes. Hence, any morphological alterations are bound to impair the vital functions, thereby resulting in hypoxaemia, hypercapnia and blood acidosis [13]. It is predicted that abnormal nuclear morphology is an indicator of genotoxic damage [11], while abnormal erythrocyte morphology is an indicator of cytotoxicity $[17]$.

Appearance of micronucleus in cell is an index of accumulated genetic damage and is one of the most suitable techniques to identify impacts of pesticide in fish [11]. However, the MN frequency is dependent upon the metabolic capacity, DNA repair efficiency and defense mechanisms of fish [18]. In general, fish are relatively sensitive to changes in their surrounding environment. Hence estimation of $\mathrm{MN}$ frequency in terms of fish health may thus reflect, and be a good indication of the health status of a specific aquatic ecosystem.

In erythrocytes of Tilapia rendalli exposed to pesticide, deltamethrin, similar increase in MN frequency was observed [19]. Similarly, Ansari et al. [20] also found that deltamethrin induced $\mathrm{MN}$ and nuclear abnormalities in erythrocytes of Channa punctata. 
Light microscopic (LM) studies provide valuable tool for identification of pesticide induced morphological alterations in fish [21]. Svobodova et al. [22] observed elongated oval-shaped erythrocytes with the peripheral nucleus in carp exposed to nitrite. Most xenobiotics have the potential to interact with erythrocyte membrane,

as seen in nonylphenol -exposed fish, consequently leading to membrane deformities [23]. In another similar study with 4-nonylphenol on adult catfish C. gariepinus, altered erythrocytes and micronucleus were detected with the aid of LM [21].

Previous SEM study on erythrocytes following cypermethrin exposure Anabus testudineus revealed abnormal erythrocytes, oozed out cytoplasmic content and lobopodial projections [13], similar to this study. Such increased membrane abnormalities may be attributed to lindane induced oxidative stress [5], which targets the cellular membrane and alter its permeability and selectivity, making the nucleus more susceptible to the formation of nuclear abnormalities and micronuclei, respectively. The vacuoles, observed in erythrocytes at higher lindane dose, could be due to unequal distribution of hemoglobin [17]. Lindane might disrupt the hemopoietin process [7] and accelerated disintegration of erythrocyte membrane may also lead to a reduction in hemoglobin and hematocrit values in the fish [24]. Oozed out cytoplasmic content and lobopodial projections were observed also in the erythrocytes after exposure to chlorpyrifos in Anabas testudineus [25].

In the present study, increase in altered cell frequencies was found to be the function of dose and duration of lindane exposure, as the increased concentrations or exposure duration registered a quantitative increase in erythrocyte aberrations. The blood cells of the fishes exposed to lindane consistently showed loss of the normal shapes and became more irregular. Cell membranes of fish are often subjected to peroxidative damage due to pesticide exposure [26] that might attribute towards the observed structural alterations. In another study on rat erythrocytes with SEM, fenvalerate exposure revealed various degrees of distortion in shape and ruptured membranes and echinocyte formation [27].

\section{CONCLUSION}

We conclude that morphological alterations in erythrocytes may result in severe physiological complications, ultimately leading to the death of fish. The present microscopic investigations de monstrated a direct correlation between pesticide exposure and erythrocyte morphological alterations and provided with useful and sensitive tool in the investigation of sublethal effects induced by environmental contaminants.

\section{ACKNOWLEDGMENT}

We thank SAIF, NEHU, Shillong and Biotech Hub, AUS, for providing electron and light microscopy facilities, respectively.

\section{REFERENCES}

1- US.EPA. United States Environmental Protection Agency, Guidance for Comparing Background and Chemical Concentrations in Soil for CERCLA Sites, EPA 540/R-01/003, 2002.

2- CIBRC. Central Insecticide Board and Registration Committee. Insecticides banned, restricted. 2015; www.cibrc.nic. (Accessed on September, 01, 2015).

3- Sarkar, UK, Basheer VS, Singh AK, Srivastava SM. Organochlorine pesticide residues in water and fish samples: first report from rivers and streams of Kumaon Himalayan region, India. B Environ Contam Tox. 2003; 70 (3): 485-493. 
4- Singh PB, Singh V. Bioaccumulation of hexachlorocyclohexane, dichlorodiphenyltrichloroethane, and estradiol-17b in catfish and carp during the premonsoon season in India. Fish Physiol Biochem. 2008; 34 (1): 25-36.

5- Pesce SF, Cazenave J, Monferra'n MV, Frede S, Wunderlin DA. Integrated survey on toxic effects of lindane on neotropical fish: Corydoras paleatus and Jenynsia multidentata. Environ Pollut. 2008; 156 (3): 775-783.

6- Barros Amorim MJ, Sousa JP, Nogueira AJA, SOARES AMVM. Bioaccumulation and elimination of 14C-lindane by Enchytraeus albidus in artificial (OECD) and a natural soil. Chemosphere. 2002; 49 (3): 323-329.

7- Saravanan M, Prabhu Kumar K, Ramesh M. Haematological and biochemical responses of freshwater teleost fish Cyprinus carpio (Actinopterygii: Cypriniformes) during acute and chronic sublethal exposure to lindane. Pestic Biochem Physiol. 2011; 100 (3): 206-211.

8- Seriani R, Ranzani-Paiva MJT, Silva-Souza AT, Napoleao SR. Hematology, micronuclei and nuclear abnormalities in fishes from Sao Francisco River, Minas Gerais state, Brazil. Acta Sci. 2011; 33 (1): 107-112.

9- Fontanetti CS, Christofoletti CA, Pinheiro TG, Souza TS, Pedro-Escher J. Microscopy as a tool in toxicological evaluations. In: Mendez-Vilas A, Diaz J. editors, Microscopy: Science, Technology, Applications and Education. Badajoz, Spain: Formatex; 2010. Vol 2. p. 1001-1007.

10- Al-Sabti K, Metcalfe C.D. Fish micronuclei for assessing genotoxicity in water. Mutat Res. 1995; 343 (2-3): 121-135.

11- Talapatra SN, Banerjee SK. Detection of micronucleus and abnormal nucleus in erythrocytes from the gill and kidney of Labeo bata cultivated in sewage-fed fish farms. Food Chem Toxicol. 2007; 45 (2): 210-215.

12- Pascoe S, Gatehouse D. The use of a simple haematoxylin and eosin staining procedure to demonstrate micronuclei within rodent bone marrow. Mutat Res. 1986; 164 (4): 237 243.

13- Velmurugan B, Selvanayagam M, Cengiz EI, Bilici S, Satar A. Surface structures of gill, scale and erythrocyteof Anabas testudineus exposed to sublethal concentration of cypermethrin. Environ. Toxicol. Phar. 2014; 37 (3): 1109- 1115.

14- Schmidt W. The micronucleus test. Mutat Res. 1975; 31 (): 9-15.

15- Massar B, Dey S, Barua R, Dutta K. Microscopy and microanalysis of hematological parameters in common carp, Cyprinus carpio, inhabiting a polluted lake in north east India. Microsc Microanal. 2012; 18 (5): 1077-1087.

16- CCAC (2005): CCAC Guidelines on the Care and Use of Fish in Research, Teaching and Testing. Canadian Council on Animal Care. http://www.ccac.ca/Documents/Standa rds/Guidelines/Fish.pdf (19 December 2012).

17- Bushra A, Abul Farah M, Niamat MA, Waseem A. Induction of micronuclei and erythrocyte alterations in the catfish Clarias batrachus by 2, 4-dichlorophenoxyacetic acid and butachlor. Mutat Res. 2002; 518 (2): 135-144.

18- Rodriguez-Cea A, Ayllon F, Garcia-Vazquez E. Micronucleus test in freshwater fish species: an evaluation of its sensitivity for application in field surveys. Ecotox Environ Safe. 2003; 56 (3): 442-448.

19- Grisolia CK. A comparison between mouse and fish micronucleus test using cyclophosphamide, mitomycin C and various pesticides. Mutat Res. 2002; 518 (2): 145150.

20- Ansari RA, Kaur M, Ahmad F, Rahman S, Rashid H, Islam F, Raisuddin S. Genotoxic and oxidative stress-inducing effects of deltamethrin in the erythrocytes of a freshwater biomarker fish species, Chann a punctata Bloch. Environ Toxicol. 2009; 24 (5): 429-436.

21- Mekkawy IA, Mahmoud UM, Sayed AEH. Effects of 4-nonylphenol on blood cells of the African catfish Clarias gariepinus (Burchell, 1822). Tissue Cell. 2011, 43(4): 223-229.

22- Svobodova Z, Machova J, Drastichova J, Groch L, Luskova V, Poleszczuk G, Velišek J, Kroupova H. Haematological and biochemical profiles of carp blood following nitrite exposure at different concentrations of chloride. Aquaculture Res. 2005; 36 (12): 1177 1184.

23- Schwaiger J, Spieser OH, Bauer C, Ferling H, Mallow U, Kalbfus W, Negele RD. Chronic toxicity of nonylphenol and ethinylestradiol: haematological and 
histopathological effects in juvenile Common carp (Cyprinus carpio). Aquat Toxicol. 2000; 51(1): 69-78.

24- Kori-Siakpere O, Oghoghene UE. Sublethal haematological effects of zinc on the freshwater fish, Heteroclarias sp. (Osteichthyes: Clariidae). African J Biotech. 2008; 7 (12): 2068-2073.

25- Velmurugan B, Selvanayagam M, Cengiz EI, Ugurlu P. Scanning electron microscopy study of the gills, scales and erythrocytes of Anabas testudineus upon exposure to chlorpyrifos. Toxicol Environ Chem. 2015; 97(2):1-13.

26- Reddy Narra M. Single and cartel effect of pesticides on biochemical and haematological status of Clarias batrachus: A long-term monitoring. Chemosphere 2016; 144 (February): 966-974.

27- Prasanthi K, Muralidhara, Rajini PS. Morphological and biochemical perturbations in rat erythrocytes following in vitro exposure to fenvalerate and its metabolite. Toxicol. In Vitro. 2005; 19 (4): 449-456. 